\title{
Vol. 70, No. 8
}

In the report "Clusters of SARS-CoV-2 Infection Among Elementary School Educators and Students in One School District - Georgia, December 2020-January 2021," on page 289, in the first full paragraph of the second column, the second sentence should have read "During this period, COVID-19 incidence (7-day cumulative number of new cases per 100,000 persons) in Cobb County, Georgia, increased almost 300\%, from 194 to $\mathbf{7 0 4}$ cases." On the same page, the footnote should have read "Incidence was calculated as a 7-day cumulative incidence per 100,000 persons using date reported and included persons with SARS-CoV-2 infection confirmed by reverse transcription-polymerase chain reaction or antigen testing." 